\title{
Resistance and boundary shear in circular conduits with flat beds running part full
}

\section{Stirling and D. W. Knight}

\section{J. Marriott, University of East London}

A paper such as this with well-documented experimental data is always useful. For those who use Manning's formula it is reassuring to see that $n$ is effectively constant over a range of depths, which must be one of the main reasons for the formula's continued popularity.

I was particularly interested by the third conclusion, which refers to the increase in resistance to flow for subcritical flow compared with supercritical, over the range tested. I wonder if this is better described as a reflection of the link between $n$ and slope referred to by Marriott and Day, ${ }^{23}$ for flows in the transitional turbulent region. In that paper, it was demonstrated that $n$ may be expressed by a relationship which is inversely proportional to slope to the power of $1 / 18$.

Taking the value of $n=0.0095$ at slope $S_{0}=0.002$ given in Fig. 3 , and applying the relationship mentioned between $n$ and slope, yields values of $n=0.099$ at $S_{\mathrm{o}}=0.001$ and $n=0.0087$ at $S_{\mathrm{o}}=0.009$. These values appear close to the average values that may be deduced from Fig. 18 .

It would be interesting to know whether the detailed data support the fact that this is a relationship with slope, rather than a result of whether the flow is subcritical or supercritical.

From the derivation of the expression linking $n$ to slope, this would not be expected to hold in the rough turbulent region, so I agree with the author's comment that this conclusion would not apply at higher values of Reynolds number.

\section{I. H. Barr, University of Strathclyde}

The authors have provided valuable new information on part full flow in circular conduits without a flat bed. There is a somewhat fragmented background to such studies. It has long been known that the observed mean velocity, $\boldsymbol{V}$, may differ to an extent from that, $\boldsymbol{V}_{\mathrm{t}}$, predicted by the text book assumption of hydraulic mean depth, or hydraulic radius, as a unique criterion of hydraulic size. Camp's ${ }^{24}$ often reproduced ${ }^{25-28}$ diagram includes what is effectively an assessment of $\boldsymbol{V}_{\mathrm{t}} / \boldsymbol{V}$ against proportional depth, $Y$, for the circumstances with which he sought to deal. It seems more logical to seek to evaluate $\boldsymbol{V} / \boldsymbol{V}_{\mathrm{t}}$, terming this the velocity ratio. Then the following form of equation derives from leads by Camp, ${ }^{24}$ Hughes $^{29}$ and Pomeroy $^{30,31}$, firstly following Hughes with radian measure.

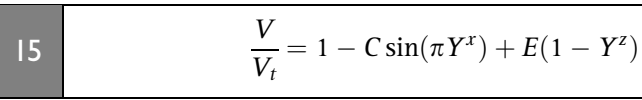

Alternatively, using degrees

\begin{tabular}{|l|l|}
\hline $15 \mathrm{a}$ & $\frac{V}{V_{t}}=1-C \sin \left(180 Y^{x}\right)^{\circ}+E\left(1-Y^{z}\right)$ \\
\hline
\end{tabular}

The inclusion of the final RHS term may not be too important but derives from Pomeroy's ${ }^{30}$ inference that $\boldsymbol{V} / \boldsymbol{V}_{\mathrm{t}}$ will become greater than 1 at very small proportional depths in a circular conduit. The writer has no direct evidence for this, but good indirect evidence is provided by the basic rectangular and trapezoidal channel results from the SERC Flood Channel Facility. ${ }^{32}$ The inclusion of the term does seem to help curvefitting of data for smaller proportional depths in circular conduits.

An evaluation of equation (15), based on findings by Ackers, ${ }^{33}$ by Kazemipour, ${ }^{34}$ and by Pomeroy, ${ }^{30,31}$ gave values of $0 \cdot 155$, $0.08,0.55$ and 0.55 for $C, E, x$ and $z$ respectively. This was thought by the writer to be reasonably suitable for comparatively smooth pipes, including new, well-laid, concrete pipes.

Extracting approximate values from the authors' Figs 17 and 19, a good fit of the very consistent data for 0.009 slope in Fig. 17 seemed to be obtained by adopting $0 \cdot 125$ for $C$, with the other values unchanged. The reciprocal process applied to Fig. 19 gave a similar correspondence.

Although the containment was unchanged, a better fit of the considerably more scattered data for 0.001 slope seemed to be obtained by reverting to $0 \cdot 155$ for $C$.

To take the matter further requires the replotting of the results on a velocity ratio against proportional depth basis, using the basic data. This can be a searching basis of analysis where the pipe full resistance law is known, as in the case of the authors' smooth turbulent tests. The foregoing requirement applied also to the analysis of Camp ${ }^{24}$ relating to flows close to rough turbulent and using the Manning formula. Camp's findings regarding invariance or otherwise of Manning's $n$ are then quite different from those of the authors. The authors' findings do correspond broadly with the design guidance of Chow, ${ }^{25}$ with constant values of Manning's $n$ quoted for smooth circular 
pipes, but these values specifically restricted to use with part full flows.

Neither the circular channel tests of Kazemipour, ${ }^{34}$ nor the tests by Kazemipour ${ }^{34}$ and by Tracy and Lester ${ }^{35}$ in smooth rectangular channels, show a clear-cut separation between the resistance results for subcritical and for supercritical flow in the same channel, as was found by the authors. This divergence may warrant further investigation.

\section{Authors' reply}

The authors thank the discussers for their comments. Professor Barr has highlighted the importance of correctly ascertaining the flow resistance. It is clearly a subject of debate how, through knowledge of the flow structure/resistance (e.g. boundary shear stress), an informed decision is made regarding the resistance parameter. The authors are aware of the fragmented background of the subject and tried to present their data in a form more in keeping with current analysis than in keeping with a historical review of the many empirical studies on this topic. The authors accept that whichever approach is adopted, a degree of empiricism will inevitably exist. However, in adjusting the mean flow velocity, any chance of understanding the flow structure is lost.

In the paper by Camp, ${ }^{24}$ to which Professor Barr refers, it is clear from Camp's Fig. 3 that the effect of a variable $n$ on the $\boldsymbol{U} / \boldsymbol{U}_{\text {full }}$ against $h / D$ relationship is an important but relatively minor one. The data presented in Fig. 18 by the authors do indeed follow the trend of Camp's Fig. 3, but with $n / n_{\text {full }}$ only reaching about $1 \cdot 15$ at $h / D=0 \cdot 2$, compared with Camp's value of around 1.30 at a corresponding relative depth. It will therefore have even less effect on the $\boldsymbol{U} / \boldsymbol{U}_{\text {full }}$ against $h / D$ relationship and precisely no effect on current design practice when designing for $0.5 \mathrm{~h} / \mathrm{D}$. In any case it is more convenient in practice to use the $n$ value for pipes running full, rather than the functional relationship for $n$ against $h / D$, which would have to be determined for every cross-sectional shape used in practice. The inclusion of the coefficient $E$ in Barr's equation (15) therefore seems to be unnecessary.

The influence of cross-sectional shape on flow structure and resistance has been a topic in which the second author has had a particular interest for a long time, and has studied in some detail-see particularly References 11, 14, 16 and 36-44.

Both Professor Barr and Dr Marriott refer to the question of whether there is a slope effect or a Froude number effect (i.e. subcritical/supercritical flow effect) on the resistance. Other data sets at Birmingham (not published) generally support the findings of Figs 17-19. The subject does indeed warrant further investigation. The authors' data does show a weak trend between $n$ and slope, but from other work it is known that the flow structures in supercritical flow are somewhat different from those in subcritical flow. Until further evidence is available, the authors therefore prefer to deal with the sub/ supercritical categories.

\section{References}

23. MARRIOTT M. J. and DAY R. A. Laboratory calibration of open channel bed resistance. Proceedings of the Institution of Civil Engineers Water and Maritime Engineering, 2000, 142, June, 63-66.

24. Camp T. R. Design of sewers to facilitate flow. Sewage Works Journal, 1946, Jan., 3-16 (also Trans Amer. Soc. Civ. Engrs, 1944, 109, 240-243).

25. Сноw V.-T. Open Channel Hydraulics. McGraw-Hill, New York, 1959.

26. Joint Committee of ASCE and the Water Pollution Control FeDERATIOn. Design and Construction of Sanitary and Storm Sewers. American Society of Civil Engineers, 1969, Manual No. 37.

27. Joint Committee of ASCE AND the Water Pollution Control FederATION. Gravity Sanitary Sewer Design and Construction. American Society of Civil Engineers, 1982, Manual No. 60.

28. Joint COMmittee OF ASCE AND the WATER ENVIRONMENT Federation. Design and Construction of Urban Stormwater Management Systems. American Society of Civil Engineers, 1992, Manual No. 77.

29. Hughes W. C. Relative velocity in a partially full pipe. Proceedings of an International Conference for the Centennial of Manning's Formula and Kuichling's Rational Formula (Yen B. C. (ed.)). University of Virginia, 1989, distributed by Water Resources Publications, Colorado, vol. on Catchment runoff and rational formula.

30. Pomeroy R. D. Flow velocities in small sewers. Journal of the Water Pollution Control Federation, 1967, 39, 15251548.

31. Pomeroy R. D. Flow velocities in pipelines. Journal of the Hydraulics Division, Proceedings of the American Society of Civil Engineers, 1983, 109, No. 8, Aug. 1108-1117.

32. KNIGHT D. W. (ed.). SERC Flood Channel Facility, Experimental Data-Phase A, Vol. 1. HR Wallingford Ltd, May 1992, Report SR 314.

33. ACKERS P. The hydraulic resistance of drainage conduits. Proceedings of the Institution of Civil Engineers, 1961, 19, 307-336.

34. KAZEMIPOUR A. K. Cross-sectional Shape Effects on Resistance to Uniform Flow in Open Channels and Non-circular Closed Conduits. PhD thesis, University of Queensland, 1979.

35. Tracy H. J. and Lester C. M. Resistance Coefficients and Velocity Distribution, Smooth Rectangular Channel. US Geological Survey, Washington DC, 1961, Water Supply Paper 1592-A.

36. LaI C. J. and KnIGHT D. W. Distributions of streamwise velocity and boundary shear stress in compound ducts. Proceedings of the 3rd International Symposium on Refined Flow Modelling and Turbulence Measurements, Tokyo, July 1988, 527-536.

37. Shiono K. and Knight D. W. Turbulent open channel flows with variable depth across the channel. Journal of Fluid Mechanics, 1991, 222, 617-646 and 231, 0ct., 693.

38. KNIGHT D. W., Al-Hamid A. A. I. and YuEN K. W. H. Boundary shear in differentially roughened trapezoidal channels. In Hydraulic and Environmental Modelling: Estuarine and River Waters (eds Falconer R. A., Shiono K. and Matthew R. G.). Ashgate Press, 1992, pp. 3-14.

39. Knight D. W., YuAN Y. M. and Fares Y. R. Boundary shear in meandering river channels. Proceedings of an International Symposium on Hydraulic Research in Nature and Laboratory, Yangtze River Scientific Research 
Institute, Wuhan, China, November 1992, vol. 2, pp. 102107.

40. Knight D. W., Yuen K. W. H. and Al-Hamid A. A. I. Boundary shear stress distributions in open channel flow. In Physical Mechanisms of Mixing and Transport in the Environment (eds Beven K., Chatwin P. and Millbank J.). Wiley, 1994, ch. 4, pp. 51-87.

41. Rhodes D. G. and KNight D. W. Distribution of shear force on boundary of smooth rectangular duct. Journal of Hydraulic Engineering, ASCE, 1994, 120, No. 7, July, 787807.
42. RhoDes D. G. and KNIGHT D. W. Velocity and boundary shear in a wide compound duct. Journal of Hydraulic Research, IAHR, 1994, 32, No. 5, 0ct., 743-764.

43. KNight D. W. and Shiono K. River channel and floodplain hydraulics. In Floodplain Processes (eds Anderson, Walling and Bates). Wiley, 1996, ch. 5, pp. 139-181.

44. KNight D. W. and ABRIL B. Refined calibration of a depthaveraged model for turbulent flow in a compound channel. Proceedings of the Institution of Civil Engineers Water, Maritime and Energy, 1996, 118, No. 3, Sept., Paper No. 11017, 151-159. 